\title{
SCIENCE IN THE MODERN WORLD: FROM VALUE TO COMPLEXITY
}

\author{
Leonid Hubersky ${ }^{1,2}$, Oksana Zhylinska ${ }^{1,3}$
}

\begin{abstract}
The paper focuses on the problem of actualizing the role of science as a complex system in the prospects of development of society and man. The development of science is shown to have led to the formation and assertion of information and digital reality. It has accelerated the pace of globalization in all spheres of life - from obtaining information to knowledge, from the expansion of visual communication to stimulating the movement of people, technology and finance. At the same time, the introduction of scientific innovations deepens the polarization of countries, continents and regions in terms of technological potential. The growing complexity of the modern world can be realized by appropriate complex thinking. The paper has revealed the main stages of formation of a new type of personality capable of understanding the complex world, independent decision-making, in the process of cognition and freedom of behavior in a situation of radical transformation of values of science and culture. The dynamics of changes in science, technology, socio-cultural and economic life is determined as well. This situation gives rise to a new "reflective society", corresponding to the initial levels of information theory of complexity, in the context of which human activity becomes non-linear, innovative and chaotic. It is emphasized that understanding the dynamics of a complex world and its systems stimulates the emergence of new approaches in management theory. In their context, the task of forming complex thinking is set, the ways of its active introduction into the culture of scientific knowledge and learning are determined.
\end{abstract}

Keywords: science; cognition; information world; complex thinking; values; technologies; knowledge

\section{The relevance of the study}

The modern world is characterized by a gap between the extraterritoriality of economic, financial, and managerial elites, for whom the civilization space is open and provides all opportunities for their mobility, and the localization and segmentation of the space for survival of the masses. Moreover, the polarization of social time is also added, in the first case being intense, qualitatively heterogeneous, vigorous, and in the second case - as extensive, homogeneous, and reduced to an abstract quantity. Due to the rupture of spatial and temporal structures, the tendencies of transformation of values, the distinction between the world of everyday life and the world dominated

\footnotetext{
1 Taras Shevchenko National University of Kyiv, Ukraine

2 https://orcid.org/0000-0002-4391-4385

3 https://orcid.org/0000-0001-8366-0474
} 
by creativity, constructivism, social and scientific rationality are growing. The gap between the world of everyday life and the world of scientific rationality, which is deepening in the context of global information and digital reality, has strengthened the alternative culture of thinking. One of the alternatives appeals to a congratulatory, direct experience, the other - to logically balanced procedures of evidentiary, correct and reasoned opinion. This issue problematizes the sphere of scientific cognition, the sphere of thinking, and the sphere of education as the most important complex systems capable of self-realization. The scientific and technological complex play an important role in the intensification of their activities, therefore knowledge has an objective significance, i.e. does not depend on the personality of its creator and user. Given the situation, the issue of clarifying the role of science as a complex system in the prospects of society and man is relevant.

The purpose of the paper is to study and identify the main criteria for resolving the contradictions caused by the dynamics of scientific knowledge and socio-cultural changes, identify the main stages of a new personality type capable of understanding the complex world, independent decision-making, freedom of behaviour in a radical transformation of science and culture.

\section{Problem statement}

The phenomenon of science has always been the focus of philosophy, theory of cognition, cultural and interdisciplinary discourses associated with the names of W. Vernadsky, A. Einstein, T. Kuhn, P. Feyerabend, K. Popper and others. M. Heidegger in the work "Science and Understanding" performs etymological and hermeneutic research, seeking to revive in it the meanings that give reality to objectivity [11]. According to A.P. Ogurtsov, the evidence of the planetary nature of science is a globalization of rational knowledge and technical means, which has led to the globalization of science itself [8, p. 461]. L. Mikeshina states that the meanings of modern science are realized in the values that are the focus of the interpretation of the specific scientific "interest" dominating in the formation of the object of scientific research [6, p. 309]. Cultural images of science are represented in the postpositivism of T. Kuhn, S. Tulmin, M. Polanyi, P. Feyerabend [12, p. 14]. In the context of philosophical analysis, science loses its absolute character and becomes consistent with historically changing, relative ideals and norms of science [4]. The comparability of science and philosophy is analyzed by A. Fagot-Largeault in the main directions of their interaction [10]. S. Pinker refers science to the realm of achievements that satisfy the interest in the world of any intellect [9, p. 385]. M. Kaku considers the role of science in the creation of artificial intelligence, which will change the nature of work and communication, the learning process, human development and the value system in general [3]. At the same time, study on the technical reconstruction of the human body is becoming increasingly important having contributed to discussions about human dignity and the criteria for the demarcation between the physical and moral-value issues. Therefore, it is especially important to study the processes of obtaining knowledge in the context of contradictions and complexities generated by science and technology of the information and digital age. 
The scientific novelty of the study is determined by the dynamics of changes in technology, socio-cultural and economic life generated by the development of science, and also information and digital technologies, which leads to the pluralization of social life and cultural values. In their context, the task of forming new, complex thinking is set, and the ways to its active implementation in the culture of scientific knowledge and learning are identified as well.

\section{Methodology}

General scientific methods and principles of philosophy of science, philosophical anthropology, philosophy of economics and social philosophy were used to analyze the problem. The principle of objectivity enabled considering the scientific developments of researchers of the problems of science and methodological reflections of cognitive activity, and also facilitated the use of theoretical discourses and arguments in historical and logical sequence. The combination of methods of phenomenology, philosophy of education, praxeology allowed revealing the specifics of the prospects for the development of scientific thinking in terms of information and digital reality. The methodology of synergetics in proportion to the interdisciplinary approach and the method of comparative studies contributed to the disclosure of the specifics of complex thinking in solving problems of productive activities of concrete-practical and abstract-theoretical semantic issues.

\section{Results of the study}

The modern global world demonstrates the expansion of a single system of values and its introduction to other regions and local cultures. Therefore, many theorists of the modern world discuss both the emergence of common values of civilization, and the formation of the ethos of the global world, the formation of a new man and a new "cosmopolitan ethics" (A. Giddens), the emergence of a new planetary class - "cosmocracy" (J. Duclos), as well as the mega-society a global community, which appears as a goal of historical development fulfilled in the trends of integration and disintegration. All these issues are conditioned by the defense of the general universals of social, political, and cultural life.

A famous sociologist I. Wallerstein connects the search for the mutual universals of socio-cultural life with the classical image of science. "The supposed rationality of the social world, as well as the supposed rationality of the physical world, presupposes the possibility of formulating provisions, like the laws that describe this world in its entirety and retaining its force in time and space. In other words, it implies the existence of universals that can be formulated clearly and beautifully, which leads to the conclusion that the task of our scientific activity is to formulate these universals and test them for strength. It is clear that this is nothing more than the adaptation of Newtonian science to the study of social realities", says the scientist [1, p. 166].

Although science and its achievements were born within local and national scientific communities, they had supranational, universal significance indeed. Thus, Mendeleev's periodic table of chemical elements, Einstein's theory of relativity, J. M. Keynes's macroeconomic theory, and many other scientific achieve- 
ments have long gone beyond national borders and have become the common heritage of humanity. Since the establishment of science as a social institution, scientists have realized themselves as equal citizens of the scientific community responsible for truth, for the practical implementation of knowledge in applied developments and technical innovations aimed at mastering the forces of nature benefiting humanity. Therefore, science retains its globalizing potential, as evidenced by the development and improvement of means of transportation, communications, information networks, mass media, etc. [8, p. 460-461].

The achievements of scientific and technological progress not only eliminated the spatial-temporal isolation of local communities, their immersion in a certain "territory of existence" with clearly defined boundaries, but also "blurred" these boundaries, turning them into national and supranational. The general direction of globalization is to create new spatial and temporal structures, which Timothy Like described as, "Space built with new technology is quite different - it is designed, not God-given, artificial space, not natural; information in it is transmitted by machines, not people, it is rationalized, not generalized, its scale is global, not local" [14, p. 123].

The development of science and information technology is associated with the acceleration of globalization in all spheres of human life - from means of communications to obtaining of information, from the expansion of the visual media to accelerating the movement of people, goods and finances. At the same time, global scientific and technological innovations deepen the polarization of countries, continents, regions concerning technical equipment and development of scientific and technological potential in terms of the degree of involvement of national communities in the international scientific community. All this testifies to the growing complexity of the modern world, which can now be understood and realized by appropriate, complex thinking.

But how possible is thinking about complexity and managing complexity? This question is posed by the German scientist Klaus Mainzer, one of the leading experts in the study of complex systems, self-organization theory, chaos theory and artificial intelligence in his work "Thinking in Complexity" (2007), which literally means "thinking about complex", i.e., thinking about the complex world created primarily by the development of science. Thus, the laws of physics discovered by science have created new conditions for everyday life, which has become qualitatively different. Therefore, these laws have become one of the "greatest triumphs in the intellectual history of humanity" [13, p. 285].

Today, our understanding of the world must be a deep comprehension of its principles, that "gravity is a distortion of space and time, and life depends on a molecule that carries information, regulates metabolism, and reproduces itself. The ideas of entropy, game theory, and artificial intelligence have created new problems, which are tested by methods of 3D-visualization of the human brain, the development of big data to track the spread of ideas. Science has also brought the gifts of health, wealth, knowledge, and freedom", says S. Pinker $[9$, p. 386].

Therefore, complex thinking must be complex to enable us to comprehend the complexities of the world in which we live. Complex thinking is a product of a complex world, and with its help we try to understand the world from 
within itself, by its own means. The properties of the world, which is endowed with complexity, and the properties that are comprehended by its thinking, are congruent. As K. Mainzer explains, "thinking in complexity" is like dancing in the rain, which "picks up the intentions and rhythm of the rain itself and merges with it into one inseparable nature" [5, p. 81].

K. Mainzer believes that the methodology of complex thinking and complex systems can be applied to systems of various natures, including human and social systems, for example, to the financial markets as stability and wellbeing of our societies depend on them. The reason is that we do not know the micromovements of economic data and agents. By analogy with the fluctuation of the value of shares as a statistical random motion (Brownian motion), in physics it is the microscopic motion of small particles. Brownian motion not only assumes statistical stability of price increases and price scales changing (i.e. invariance of ratios when shifting or scaling), but also independence of price growth cases (it is known that the past does not give us knowledge of the future), continuity of price changes as a continuous curve), rough uniformity of change of prices (normal Gaussian distribution), absence of creation of clusters (absence of emergence of local patterns and structures) and absence of cyclic behavior. Based on this, the Gaussian distribution leads to the idea of an efficient market, successful buying and selling of securities with doubling prices: whether we know the past completely, partly or it is not known at all, price changes throughout the future, which is seen as expectations [5, p. 92-93].

The analysis of the complexity of the financial process has contributed to the development of modern theory and practice of financial activities. Financial markets reveal some properties similar to fluid turbulence. Like fluctuations in turbulent fluid, financial fluctuations demonstrate the property of repeatability on all scales. During the process of turbulence in fluid, energy flow cascades are known to occur on different scales: both on a larger scale of influence and on a small scale of dissipation. If we apply a nonlinear and fractal approach to the financial system, then randomness can no longer be limited to the "normal" distribution of price changes. "Non-normal" distributions are more appropriate to describe the "wild" turbulence of financial markets. Therefore, it is necessary to consider the level of randomness [5, p. 94].

The complexity of the processes of the modern era is supplemented by a new way of developing human civilization - "informationalism" (M. Castells). Human activity in the context of the emergence of a new, informational and communicative way of development necessarily acquires a significantly nonlinear, innovative and cyclical nature. In its content, it becomes an activity of "creative communicative construction of new active nonlinear environments of complex realities that intersect and reproduce: material, informational, sensory-emotional, sign-symbolic, intellectual and spiritual", says L. S. Gorbunova [2, p. 37].

We are referring to the formation of a new "reflexive society", the most dynamic and chaotic in nature. The transition from ordered to chaotic systems corresponds to the growing complexity of information and computational problems, correlating with the initial levels of information-computational theory of complexity. Dynamic and therefore chaotic systems can be considered as deterministic, stochastic, or quantum computers that process information 
about present and future states based on initial conditions using appropriate dynamic equations. By its nature, quantum information provides only probabilistic predictions of future states [5, p. 94-95].

Thus, to live and act in new conditions, you need a different way of thinking, a different way of acting. But developing complex thinking logic adequate to complex changes is not easy, because it implies new values and new rules of practical life. It is not possible to adapt to the new reality so quickly, therefore it is necessary to understand it, comprehend, and find the corresponding rational way of activity. However, to do so, using the usual thinking and skills of industrial culture, even in the 20th century, is not only ineffective but also dangerous. In this situation, when almost a quarter of the 21st century has passed, we cannot go further without developing a new type of thinking, and with it, - new values and their new perception [2, p. 37-38].

The need to generalize and form complex global thinking is determined by a new paradigm of the world process associated with the development of the modern scientific revolution 4: 0 , which has led to the formation of postclassical science. Unique, complex systems that are developing dynamically, where the man himself is the main component, are in the very center of its research. However, the complexity and dynamic nature of the object of scientific research (complex, open systems), the diversity of the content of its subjective component form a situation of pluralism and competition of research programs and projects that are deployed in the interdisciplinary field. This demonstrates the space of complex thinking outside of disciplinary and "simplified" paradigms focused on reduction and division (for example, human to natural and between human and natural). But such an understanding hinders the realization of the man's modern attitude to nature [2, p. 42].

Only a complex paradigm enables developing a complex thinking corresponding to it. The Internet is the modern paradigm. The complexity of the global network means the growing number of personal computers, servers, quantum computers that interact by transmitting information on the Internet as well. Numerous "smart" devices are distributed in the intellectual environment of our daily lives. Concerning complex systems, strength arises from their mutual collective interaction. Thus, "complex", scientifically oriented thinking acts as a connecting, i.e. interdisciplinary, communicative one, forming the ability of creative competence. At the metascientific level, comprehensively exploring complex objects, transferring cognitive models from one disciplinary field to another, developing a common language of science, demonstrating metaparadigmatic universals, complex thinking becomes transdisciplinary one $[2$, p. 44].

The result is a synthesis of the natural, social and human sciences, creating a single view of the world. Its specificity is that it is rather a moving hologram of the world, revealed from the place of man in it and its trajectory. But a new picture of the world is possible only in the context of asserting the paradigm of complexity of the world and man, nature and its roots, belonging to it, and therefore its corresponding human existence, which constructs the second, "artificial" nature of technology and social institutions in its collective formation.

In such circumstances, there is a transition from "complexity" to "complication", and consequently thinking is also complicated. Substantiating the 
need for reform of thinking, E. Morin identifies two main aspects from many aspects of complexity in thinking. The first is the combination of elements and parts with the formation of a single whole with new properties (holism). The second determines that any cognition, phenomenon, thinking or structure in nature or society contains deep contradictions that constantly form a complex, and complicate reality [7]. Complex thinking is therefore more productive, because it constantly balances on the verge of crisis and stability, chaos and order, goes from simple to complex and complicated, opening new horizons for understanding the world.

Understanding the dynamics of a complex world and its systems stimulates the emergence of new approaches in management theory. The impressive complexity of the world, the growing pace of economic, geopolitical, social change, the uncertainty of the future force a person as a subject of social activity to be more flexible, able to adapt to the situation and change his strategy depending on changing conditions. Understanding the trends of scientific and technological development is now impossible without an in-depth analysis of the theory of complex systems, the general patterns of the birth of order from chaos. As the value approach dominates scientific cognition today, the subject of scientific cognition, when making decisions, is forced to consider different value vectors, use his personal knowledge and heuristics developed on the basis of cognitive experience. That is the essence of complex thinking as a process and trend.

\section{Conclusions}

The achievements of modern civilization are stipulated by the development of science. It has radically changed the material, cultural, and intellectual life. Scientific discoveries provide answers to questions that open up prospects for the continued existence of humanity. Due to the colossal influence of scientific and technological advances the world has become complex, which determined the nature and possibilities of thinking. In order to comprehend the complexity of the modern world, thinking must also be complex. This means nonlinearity, openness, and consequently invariance, inclusion in the complex structure of the world in spatial and temporal aspects. Penetration into the understanding of the dynamics of complex systems determines the development of complexity management technologies, which is possible due to complex thinking. Complex thinking creates a new dynamic image of the world, which is self-organizing, with man involved in it.

\section{References}

[1] Wallerstein I., 2004. World-System Analysis : an introduction. Durham: Duke University Press.

[2] Horbunova L. S. 2011. Skladnisne myslennya yak vidpovid na vyklyk epokhy: filosofiya i metodolohiya rozvytku vyshchoyi osvity Ukrayiny v konteksti yevrointehratsiynykh protsesiv. Kyiv : Pedahohichna dumka. [Complex thinking as a response to the challenge of the era: philosophy and methodology of higher education development in Ukraine in the context of European integration processes]. [in Ukrainian]. 
[3] Kaku M. 2014. The Future of the Mind: The Scientific Quest to Understand, Enhance, and Empower the Mind. New York : Doubleday.

[4] Knyazeva Ye. N. 2010. Kak vozmozhno myshlenie o slozhnom i upravlenie slozhnost'ju. Voprosy filosofii, no. 10:81-83. [How Complex Thinking And Managing Complexity Is Possible]. [in Russian].

[5] Mayntser K. 2010. Vyzovy slozhnosti v XXI veke. Mezhdistsiplinarnoye vvedeniye. Voprosy filosofii. no. 10:84-98. [Challenges of complexity in the XXI century. Interdisciplinary introduction]. [in Russian].

[6] Mikeshina L. A. 2008. Filosofiya poznaniya. Problemy epistemologii gumanitarnogo znaniya. Moskva : «Kanon+ ROOI «Reabilitatsiya». [Philosophy of knowledge. Epistemology problems of humanitarian knowledge]. [in Russian].

[7] Morin E. 1992. Method: towards a study of humankind. Vol.1. The nature of nature. New York, Berlin, Bern, Frankfurt. M., Paris, Wien : Peter Lang.

[8] Ogurtsov A. P. 2011. Filosofiya nauki: dvadtsatyy vek: Kontseptsii i problem. V 3-kh chastyakh. Chast vtoraya: Nauka v sotsiokulturnoy sisteme. Sankt-Peterburg: «Mír». [Philosophy of Science: Twentieth Century: Concepts and Problems]. [in Russian].

[9] Pinker S. 2019. Prosvitnytstvo sohodni. Arhumenty na koryst rozumu, nauky i prohresu. Kyiv : Nash format. [Enlightenment today. Arguments in favor of reason, science and progress]. [in Ukrainian]

[10] Fagot-Largeault A. 2009. The Legend of Philosophy's Striptease (Trends in Philosophy of Science). French Studies in the Philosophy of Science : Contemporary Research in France. Dordrecht : Springer Netherlands: $25-49$.

[11] Heidegger M. 2013. Being and time. [United States]: Stellar Books.

[12] Khramova V. L. 2011. Kul'turologicheskiye obrazy nauki v postpozitivizme. Sofiya : Kulturolohichnyy zhurnal. no. 11:14-58. [Cultural images of science in post-positivism]. [in Russian].

[13] Carroll S. 2016. Breakthrough: The Saga of Jonas Salk. Trident Press.

[14] Like T. 1996. Identity, Meaning and Civilization: Detraditionalization in Post-Modern Space-Time Compression. Detraditionalization. Oxford.

[15] Mainzer K. 2007. Thinking in Complexity. The Computational Dynamics of Matter, Mind, and Mankind. New York : Springer. 